\title{
A ESCOLA INVADE AS RUAS: PASSEATAS CÍVICAS DOS GRUPOS ESCOLARES SERGIPANOS - CIVISMO E PATRIOTISMO NO ESPAÇO URBANO
}

\author{
Degenal de Jesus da Silva ${ }^{1}$ \\ lattes.cnpq.br/9766507554001047
}

\begin{abstract}
Resumo: Este artigo apresenta a pesquisa sobre as festas cívicas realizadas nas ruas de Sergipe, entre 1923 e $1930^{2}$. Nesse intervalo temporal, aconteceu algo inusitado, e os historiadores sergipanos não se debruçaram a estudar: o declínio das comemorações republicanas nas ruas. Este estudo ganha relevância, principalmente, porque se sucedeu no governo de Graccho Cardoso a presidente do estado, considerado pela historiografia sergipana como um governante desenvolvimentista, especialmente, na área da educação. Assim, o objetivo é examinar o percurso das festividades, tentando perceber os indícios deixados nas fontes sobre as formas de participação de indivíduos e instituições envolvidos nesses momentos de celebração; e, as representações utilizadas naquele momento histórico. Para tanto, utilizamos diversos documentos para que pudéssemos cruzar as informações, com o intuito de podermos lançar um novo olhar sobre esse período. Dessa forma, utilizamos os conceitos de Representações, de Roger Chartier; de indivíduos, de Norbert Elias; e do paradigma indiciário, de Carlo Ginzburg.
\end{abstract}

Palavras-chave: Festas Cívicas; Primeira República; Representações.

\section{THE SCHOOL INVADE STREETS: PARADES CIVIC OF THE SERGIPEANS GROUPS SCHOOL - CIVILITY AND PATRIOTISM IN URBAN SPACE}

\begin{abstract}
Article search civic parties in Sergipe held in the streets, between 19231930. In this time interval, there was something unusual, and that the Sergipeans historians pored studying: the decline of republican celebrations in the streets. This study becomes relevant, especially because this fact began under President Cardoso Graccho the President of the State, considered by sergipana historiography as a developmentalist - and especially in education. The objective is to examine the course

\footnotetext{
${ }^{1}$ Mestre em História pela Universidade Federal de Sergipe (Brasil). Contato: degenal2-013@yahoo.com.br.

2 Este artigo é um desdobramento de parte da minha dissertação apresentada ao Programa de Pós-graduação em História da Universidade Federal de Sergipe, intitulada Dionísio republicano: as festas dos grupos escolares sergipanos e os outros olhares (1911-1930).
} 
of the festivities, trying to understand the clues left in the sources of the forms of participation; individuals and institutions involved in these moments of celebration; and the representations used in that historic moment. Therefore, we use various documents so that we could cross the information, In order that we can launch a new look at this period. Thus, we used the concepts: Representations of Roger Chartier; individuals of Norbert Elias and the indiciary paradigm of Carlo Ginzburg.

Keywords: Civic Parties. First Republic. Representations.

O que é a festa? Podemos classificá-la com precisão? Tal pergunta encontra diversos obstáculos, de modo que nos limitamos a refletir sobre a extensão e os objetos nos quais se enquadra, ou melhor, quais eventos podemos denominar como festa. Se as diversas solenidades (rituais políticos entre outros) podem ser alegres ou tristes, sendo que isto depende do olhar do historiador e do acontecimento em tempo e espaço determinado (DURKHEIM, 2013; LUZ, 2012).

Visto que um dos princípios, que encontra certo consenso ou que seja menos criticado, pode ser desconsiderado em algum momento a fim de realçar a peculiaridade histórica de determinada festividade. Dessa forma, tomamos como exemplo a comemoração de 08 de dezembro de 1924, a qual o presidente de Sergipe, o sr. Graccho Cardoso, tornava pública a celebração a Abílio Cesar Borges. Indivíduo que contribuiu para os estudos sobre a educação e para sua difusão, por sua vasta produção, a língua portuguesa. Tornando-se feriado em todo o país por ordem do Presidente da República, o dr. Epitácio Pessoa.

Feito comemorado apenas uma vez no período em que a dissertação se debruçou (1911-1930). Quebrando assim a afirmação de que o evento, para ser uma festa, deveria ser recorrente, ou seja, cíclica (SILVA, 2015, p. 196). Mostrando que certos objetos de estudo na história não são muito afeitos a regras fixas. Afinal, elas sofrem a ação do homem no tempo e, em determinado espaço, ao sabor de certas circunstâncias.

Foram nessas irregularidades que os festejos cívicos ocorreram em Sergipe. Em Dionísio republicano: as festas dos grupos escolares 
sergipanos e os outros olhares (1911-1930), embora não estivesse inserida na data limite, percebemos que, antes de 1911, as festividades republicanas eram alvo de constantes reclamações ou ausência de comemorações. Restringindo-se muitas vezes a um ritual mais simples, como o hasteamento e descimento das bandeiras.

Desde a promulgação do decreto em que se tentou implantar um sistema de festas no país até a realização delas neste Estado, percebemos que não alcançaram os resultados esperados (18901910). Em diversos momentos não foram organizados tais eventos nas ruas, quando muito, resumiam-se a um breve hasteamento das bandeiras nas Instituições públicas. Ademais, não temos informação suficiente - por enquanto - o que motivou as reiteradas declarações da apatia dos sergipanos para as questões cívicas e patrióticas (SILVA, 2015, p. 54).

Nesse cenário, vários indivíduos expunham suas críticas por meio da imprensa sergipana - isso quando o próprio jornal não o fazia. Conclamando a sociedade a participarem mais dos festejos, comparecendo e apoiando os eventos republicanos; ou seja, legitimando os ideais difundidos nas comemorações que o novo regime mandava guardar. Haja vista que mesmo com o comparecimento de uma grande quantidade de espectadores, seus organizadores destacavam a frieza de tais momentos. Sobre quais critérios eles se fundamentavam para fazerem essa afirmação não está explícito ou implícito na documentação.

Verificamos que entre 1911 e 1916, as celebrações apresentavam maior regularidade nas festas cívicas de ruas. O auge dos eventos republicanos ocorreu entre 1917 a 1922. Depois desta data, as comemorações nos espaços urbanos declinaram abruptamente, a ponto de quase estagnaram. Se comparado aos anos anteriores, restringiram-se a um ritual por demais simplório: de hasteamento e descimento das bandeiras nos feriados cívicos.

Dantes, a cidade toda se remexia e vinha assistir às ruas principaes o seu movimento incommun suscitado pelas comemorações cívicas ao dia; em que sobre-sahiam as forças militares em evoluções, e o desfile das escolas. etc. [...]. Nada disso se faz. O governo, o tempo que dispõe, emprega 
unicamente em vender (quando não dá) o patrimônio do Estado [...] (SERGIPE JORNAL, 1926, p. 2).

Seu declínio aconteceu no governo de Graccho Cardoso, presidente de Sergipe. Logo após assumir a administração do estado, as festas cívicas nas ruas cessaram. Algo contraditório, pois ele foi/é considerado por muitos, inclusive pela historiografia sergipana atual, como um governante desenvolvimentista. Sendo responsável por diversas construções públicas, voltadas principalmente à área de educação - os grupos escolares.

Essa situação perdurou durante muitos anos. Atingindo, aliás, o sucessor de Graccho Cardoso ao governo do estado, o sr. Manoel Corrêa Dantas. Um período relativamente longo, em que não houve a realização das festividades cívicas nas ruas, que se iniciou em 1923, durante a administração de Cardoso, alcançando, inclusive, o final do mandato do presidente Dantas em 1930. Sendo que neste ano, há indícios que elas estavam retornando.

No período em questão (1923-1930), percebemos o silêncio das autoridades sergipanas ao tomarem medidas para que as comemorações acontecessem. O que motivava esse desinteresse, não sabemos as razões. Simplesmente, houve a omissão de dois presidentes de Sergipe (Graccho Cardoso e Manoel Corrêa Dantas) para que elas ocorressem.

O último presidente de Sergipe da década de 1920, não esboçou nenhuma preocupação ou reação frente às festas republicanas de rua. Sua preocupação estava voltada, durante seu mandato, para a realização delas no interior dos estabelecimentos de ensino primário. Sendo que em 1927, o sr. Corrêa Dantas, reforçava na Assembleia Legislativa, a importância das comemorações nacionais e estaduais nas escolas.

Mas as autoridades sergipanas não foram as únicas a silenciarem frente a uma situação no mínimo inquietante. Tendo em vista não existir nenhum indício na documentação sobre o porquê, e, muito menos, discursos nos ofícios, decretos e regulamentos da instrução que façam qualquer referência às festividades organizadas no espaço urbano naquele período. 
Entre os que silenciaram estava a imprensa sergipana. Sem as comemorações cívicas nas ruas, com a participação das várias escolas públicas e as diversas instituições de Sergipe, os jornais voltaram seus olhares para o que era realizado nos outros entes federativos, a exemplo de Pernambuco, Bahia e Rio de Janeiro. Foi um período em que a sociedade sergipana teve que conviver com essa situação de desânimo em diversos setores sociais - com exceção de algumas instituições de fomentação da cultura.

O que nos levou a concluir que o período de 1923 a 1929, encontrava-se em situação bem mais precária do que os anos anteriores a 1911. Nestes havia comemorações, e os indivíduos ou o próprio jornal posicionavam-se quanto aos diversos assuntos referentes às celebrações republicanas: a frieza dos espectadores, a falta de regularidade da realização das festas, o incentivo ao civismo e a conclamação de um maior número de indivíduos nos festejos.

No período de estagnação (1923-1928)3, as vozes silenciaram. Os sergipanos apenas tomavam conhecimento das festividades pelo hasteamento de bandeiras, quando aconteciam, ou pelas notícias nos jornais de outros estados. Não houve pronunciamentos ou manifestações de indivíduos na imprensa e nem notas emitidas pelos próprios jornais, com exceção de uma única nota no Sergipe Jornal, de 08 de setembro de 1926, e de alguns discursos realizados pelo Instituto Histórico e Geográfico de Sergipe (IHGSE), no Jornal Correio de Aracaju, para que os sergipanos se interessassem pelas comemorações.

Esse marasmo dos festejos cívicos nas ruas não foi uma ocorrência, apenas, de um momento da história da Primeira República em Sergipe. José Veríssimo, no Jornal O Liberal do Pará, já alertava para a falta de fervor cívico-patriótico. Segundo ele, no Brasil Império, as grandes datas nacionais passavam despercebidas, quase esquecidas, "[...] o povo vê-a

\footnotetext{
3 Nesse período (1923-1928) as comemorações nas ruas estagnaram. Em 1929, teve uma celebração com a participação de diversas escolas, embora Manoel Corrêa Dantas afirmasse que foram duas - a esse respeito veja a discussão em SILVA (2015) -, e, em 1930, pelos indícios que temos, os festejos ressurgiram no espaço urbano.
} 
passar todos os annos com um indiferentismo glacial” (VERÍSSIMO, 1879, p. 1).

No ano seguinte à Proclamação da República (1889), foi regulamentada, por decreto, as festas que deveriam ser comemoradas. Nesse ato do governo, José Veríssimo demonstrou otimismo pela realização delas de forma regular (REPUBLICA DOS ESTADOS UNIDOS DO BRASIL, 1890, p. 265) e apelou para que, "não os deixemos cair logo em desuso, como na monarquia” (VERÍSSIMO, 1890, p. 83). Posteriormente, ele se decepcionou com o regime republicano.

No caso de Sergipe, isso pode ser demonstrado pelo Decreto n. ${ }^{0} 155$ $\mathrm{B}$, de 14 de janeiro de 1890, que sancionou os festejos republicanos, contudo, a ocorrência delas variou no estado. No percurso até 1930, encontramos quatro fases: 1) 1890 a 1910, momento em que elas aconteciam de forma irregular, verificado pelas notas nos jornais acusando os sergipanos de expressarem um baixo fervor cívicopatriótico. Além de não ter a participação ativa das escolas públicas. 2) 1911 a 1916, os estabelecimentos de ensino começaram a participarem de forma ativa - principalmente, os grupos escolares. Nesse período, continua as reiteradas reclamações da frieza dos indivíduos para com as comemorações. 3) 1917 a 1922 foi o auge dos eventos cívicos, realizados com muita pompa, em que participaram deles diversas instituições. Nesse momento cessaram as reclamações sobre a frieza da sociedade sergipana para com as festas cívicas. 4) 1923 a 19304, elas praticamente estagnaram. Torando-se um evento de hasteamento e descimento de bandeiras, com exceção de algumas instituições, os jornais silenciaram. Não houve reclamações - de indivíduos ou dos próprios jornais - sobre o marasmo das celebrações (SILVA, 2015, p. 217-218).

A organização dos eventos cívicos, pelo percurso apresentado, estava se tornando complexa, pois exigia o envolvimento de uma gama maior de instituições e indivíduos na execução e participação. Sendo que

\footnotetext{
4 Em 1929, foi realizada uma comemoração nas ruas, mas entendemos que não foi o suficiente para afirmarmos sobre o retorno das festas cívicas e cívico-escolares. Pelos indícios encontrados, elas começaram a ganhar força a partir 1930. (SILVA, 2015).
} 
nos dias comemorativos, arrolavam sujeitos de diversos lugares e classes sociais. Talvez por isso, e também pela grandiosidade em que eram organizados tais eventos, não foram ouvidas, naquele período (19171922), aquelas vozes dissonantes que gritavam sobre a frieza dos sergipanos nos eventos republicanos.

Passado esse momento de auge, as festas cívicas na urbe continuaram. Muito embora, anteriormente, eram vários estabelecimentos de ensino que marchavam no espaço urbano. Posteriormente, só vamos ter informações de comemorações de ruas pelas passeatas cívico-escolares. Uma escola, uma passeata5. Se comparadas aos anos anteriores, a forma como era realizado esse evento, naquele momento, as batidas das bandas de música e o marchar dos grupos escolares, assemelhavam-se a sussurros nas ruas.

Como espelhos da sociedade a ser formada, as passeatas cívicas eram organizadas para apresentarem os resultados da educação no estado. As festas, entretanto, mais do que mostrarem, era uma forma pedagógica - estratégica - de incutir nos indivíduos, especialmente, nos discentes e no público em geral, comportamentos, hábitos, gestos e palavras de ordem (civismo e patriotismo).

Elas foram organizadas para tornarem-se espetáculos, sedutoras, agradáveis aos olhos, despertando sentimentos de negação com algumas práticas utilizadas em sociedade. Tal sensação de vergonha ou coerção deveria gerar nos alunos e em seus pais um autocontrole que os fizesse se voltarem ao trabalho; cultuarem os heróis da pátria; obedecerem às autoridades do estado que ali se faziam presentes - hierarquia; e defenderem a pátria quando fosse necessário, entre outras coisas. Forjar o cidadão e formar a nação exigiam entrega total dos indivíduos aos ideais do regime republicano.

Ao tentarem impor, por meio dos festejos, uma sociedade idealizada em Sergipe, distanciavam-se da vida real. Elas não poderiam ser analisadas como espelhos de certo período, trazendo à tona o cotidiano e a relação dos indivíduos no meio social. Longe de ilustrar a cultura de de-

5 Em alguns casos, há notícias da união de duas escolas realizando passeatas cívicas. Mas esta situação era muito rara. 
terminado período e espaço, contrariavam seus elementos e dela se destacavam, forjando uma imagem idílica a ser construída (DUVIGNAUD, 1983, p. 32).

As ruas e praças das urbes sergipanas eram os lugares privilegiados para tais encenações. Paralelamente, nesse período, a partir de Aracaju, as cidades passavam por um processo de remodelação de seus espaços. Com a realização das passeatas cívicas das escolas no estado, tais cenas vieram reforçar os novos comportamentos e hábitos que deveriam ser gestados em tais ambientes.

O que haveria de vigorar numa cidade que passava por transformações, objetivando se tornar civilizada, seria a erradicação de certo contexto, existente bem antes de 1911, que atravessou o Período Imperial: prostituição, vadiagem, roubo, furtos, entre outros vícios. Entretanto, não se destinavam apenas a lugares de passagem ou de recreações. Haveriam de ser lembradas e usadas para práticas civilizadas dos cidadãos republicanos, como festas cívicas, comemorações, celebrações, passeatas cívicas, homenagens entre outras.

Para que isso acontecesse, os festejos não poderiam cair em desuso como nos tempos da monarquia (VEIGA, 2007, p. 414). Naquele momento, eles estavam sobre a égide de escolas isoladas do Império. Em tais estabelecimentos de ensino, não se podia ter nem uma educação cívica e nem uma preparação para satisfazer as necessidades da vida ou para desempenhar as funções sociais que a República impunha. Eram muito deficitárias para construírem e legitimarem práticas e representações que o novo regime idealizava (CARVALHO, 1989, p. 24-25).

Segundo Mona Ozouf, as festas seriam como uma dócil maquinaria, pronta para ser montada e desmontada "[...] num abrir e fechar de olhos, tendo em vista as necessidades da causa” (OZOUF, 1976, p. 224). Pois, quantos sejam os propósitos políticos tanto eram as comemorações a serem organizadas. Sendo que para a autora nem todas seriam iguais. Haveria uma tipologia: festas revolucionárias, contestatórias, desregradas, entre outras; mesmo semelhantes, poderiam esboçar intenções antagônicas de seus organizadores (OZOUF, 1976, p. 220). 
Contudo, com a construção dos grupos escolares em Sergipe, as comemorações nas ruas oscilavam entre momentos de euforia (19171922), de certa regularidade (1911-1916) e de quase estagnação (19231930). Assim, compreendemos que a afirmação de Mona Ozouf, foi exagerada, hiperbolizando a festa a uma mera montagem facilmente realizada por seus organizadores. Ao fazer isso, acabavam desconsiderando os vários fatores que poderiam influir em sua organização, como: conflitos políticos, econômicos, sociais e o próprio interesse do público sobre tais festejos.

Na situação em que as comemorações em Sergipe estavam, o sr. Manoel Corrêa Dantas, transformava, segundo seu projeto, a escola de ensino primário - principalmente os grupos escolares - em principais instrumentos de execução dos ideais republicanos. Ao fazer isso, pesava sobre seus ombros a construção de representações (conhecimentos escolares) e práticas civilizadas (hábitos, costumes, gestos e outros) a serem ensinadas e legitimadas por meio das festas cívico-escolares e escolares.

Foi nesse contexto que a comemoração realizada no Grupo Escolar Olympio Campos, em 7 de setembro de 1927, aconteceu. Depois de várias solenidades e atividades com a participação dos alunos, a escola preparava-se para invadir as ruas. Pois, à tarde, esse estabelecimento de ensino fez uma passeata cívica, acompanhada de uma banda de música local, juntamente, com a Escola Tobias Barreto que se incorporou ao desfile (CAMPOS, 1927, p. 1).

Por conseguinte, na ausência de comemorações em que houvesse a participação de várias escolas sergipanas, tais empreendimentos tornavam-se competência de professores e diretores dos grupos escolares (1923-1930). Doravante, competiam-lhes planejar e executar os festejos, o que possibilitou que gozassem de certa liberdade para escolherem se as festas nas escolas graduadas seriam mais simples ou mais elaboradas, seguidas ou não de passeatas cívicas nas ruas da cidade.

Na prática, embora sutil, representava a transformação em um dos objetivos da festa. Por um lado, em um primeiro momento, temos diversas escolas encenando o progresso da instrução em Sergipe; por outro, havia escolas organizando as comemorações de forma particular. Nesse 
caso, mais do que representarem o desenvolvimento do ensino primário, mostravam a importância da instituição escolar que a realizava. Possibilitando também adquirir visibilidade tanto na localidade como em nível estadual, os grupos escolares que as organizassem, principalmente, para fora de seus muros, por meio de passeatas cívicas (CAMPOS, 1927, p.1).

Ao fim de nossa análise, percorremos os caminhos trilhados pelas passeatas cívicas no estado. Antes dos grupos escolares em 1911, eram realizadas, geralmente, com a ajuda de certos indivíduos ou instituições privadas. Entre 1911 e 1922, foram frequentes sua inclusão nas festas organizadas pelo governo com a participação de vários estabelecimentos de ensino. Após essa data, voltavam às ruas de forma individual: uma passeata cívica, uma escola. Para finalmente, a partir de 1930, surgir indícios de que as comemorações cívicas estavam retornando.

Desse modo, compreendemos que os alunos dos grupos escolares no estado exerciam paralelamente dois papéis. Eram forjados pelas festas cívico-escolares, especificamente nas passeatas, ao mesmo tempo que contribuíam para a construção de uma representação de civilidade. Nesse sentido, coube a professores, diretores dos grupos escolares e discentes darem prosseguimento - entre 1923 e 1930 - às grandes festividades cívicas de rua organizadas no passado, mesmo que sejam apenas uma lembrança do que já foram.

\section{Referências}

LUZ, Guilherme Amaral. Festa barroca? In: PEREZ, Léa Freitas; AMARAL, Leila; MESQUITA, Wania (Orgs.). Festa como perspectiva e em perspectiva. Rio de Janeiro: Garamond, 2012. p. 337-351.

BURCKHARDT, Jacob. A sociabilidade e as festividades. In: . A cultura do renascimento na Itália: um ensaio. Tradução: Sérgio Tellaroni. São Paulo: Companhia das Letras, 2009. p. 360-371.

CARVALHO, Marta Maria Chagas de. A escola e a república. São Paulo: Brasiliense, 1989. 
CHARTIER, Roger. Introdução. A História Cultural: entre práticas e representações. Tradução: Maria Manuela Galhardo. Lisboa: Difel, 1990. (Memória e Sociedade).

DURKHEIM, Émile. As formas elementares da vida religiosa. Tradução: Paulo Neves. 3. ed. São Paulo: Martins Fontes, 2003.

DUVIGNAUD, Jean. Introdução. In: - Festas e civilizações.

Tradução e Nota introdutória: L. F. Raposo Fontenelle. Fortaleza: Edições Universidade Federal do Ceará, Rio de Janeiro: Tempo Brasileiro, 1983. p. 32.

ELIAS, Norbert. $O$ processo civilizador: uma história dos costumes. Volume I. Tradução: Ruy Jungmann. 2. ed. Rio de Janeiro: Zahar, 2011. GINZBURG, Carlo. Sinais: raízes de um paradigma indiciário. In: . Mitos, emblemas, sinais: morfologia e história. Tradução:

Federico Carotti. São Paulo: Companhia das Letras, 1989. p. 143-180.

OZOUF, Mona. A festa sob a Revolução Francesa. In: ; LE GOFF, Jacques; NORA, Pierre. História: novos objetos. Tradução: Terezinha Marinho. Rio de Janeiro: F. Alves, 1976. p. 216-232.

PEREZ, Léa Freitas; AMARAL, Leila; MESQUITA, Wania (Orgs.). Festa como perspectiva e em perspectiva. Rio de Janeiro: Garamond, 2012.

SILVA, Degenal de Jesus da. Dionísio republicano: as festas dos grupos escolares sergipanos e os outros olhares (1911-1930). 238 f. Dissertação (Mestrado em História). Universidade Federal de Sergipe, São Cristóvão, 2015 .

VEIGA, Cynthia Greive. Educação estética para o povo. In: LOPES, Eliane Teixeira; FARIA FILHO, Luciano Mendes. 500 anos de educação no Brasil. 3. ed. Belo Horizonte: Autêntica, 2007. p. 414.

\section{Fontes}

SERGIPE JORNAL. Ano VI, n. 1417, Aracaju/SE. o8 de setembro de 1926. p. 2.

VERÍSSIMO, José. Aos domingos. O Liberal do Pará. Ano XI, n. 9, Belém/PA. 12 de janeiro de 1879. p. 1. 
CAMPOS, Arthur Alfredo. [Ofício]. o8 de setembro de 1927, Aracaju/SE [para] diretor da Instrução Pública, Sergipe. $1 \mathrm{f}$.

REPUBLICA DOS ESTADOS UNIDOS DO BRASIL. Decreto n. ${ }^{0} 155$ B de 14 de janeiro de 1890. In: OCTAVIO, Rodrigues. As Festas Nacionaes. F. Briguiet \& C. Editores, 1893. p.265.

VERÍSSIMO, José. A educação nacional. 4. ed. Rio de Janeiro/RJ: Topbooks; Belo Horizonte/MG: Puc-Minas, 2013.

Recebido em 15 de abril de 2016. Aprovado em 15 de julho de 2016. 